\title{
Digital-Visual Stakeholder Ethnography
}

\section{Sarah Pink, Kerstin Leder Mackley, Nadia Astari and John Postill}

\begin{abstract}
In this article we discuss how new configurations of stakeholders are implicated and can be conceptualised in digital-visual applied and public ethnography. We set the discussion in the context of the increasing calls for researchers to have impact in the world, and the ways that digital technologies are increasingly implicated in this. In doing so we situate ethnographic practice and stakeholder relationships within a digital-material world. To develop our argument we discuss examples of two recent digital video ethnography projects, developed in dialogue with anthropological theory, with online digital-visual applied and public dissemination outputs. As we show, such projects do not necessarily have one direct applied line, but rather can have multiple impacts across different groups of stakeholders.
\end{abstract}

\section{Keywords}

Digital ethnography; visual ethnography; applied practice; stakeholders in research; environmental sustainability; impact.

\section{Introduction}

In a context of 'digital materiality', whereby the digital and material can no longer be seen as separate elements of our everyday environments and practice (Pink, Ardevol and Lanzeni 2016) new forms of applied and public scholarship and practice are emerging. On the one hand, there are calls for academic researchers to have impact in the world, and on the other the possibilities of digital and visual technologies for ethnographic practice. We argue that attention to these shifts offers new possibilities for how we can understand and activate potential forms of impact for and with stakeholders, through new interdisciplinary theory-practice interfaces. We discuss, as examples, two recent projects that go beyond existing practice in two ways: they combine applied, public academic and pedagogical dissemination outputs; and also differ from existing developments in this field because they bring together anthropological ethnography with design, ethnographic documentary making and visual-digital dissemination strategies. Anthropology provides a good example precisely because it is a discipline where applied/public, visual, design and digital anthropologies have convincing existing literatures. However departs from these disciplinary origins to postulate for further interdisciplinary pathways.

Anthropologists have reflected on urges for ethnographic practice to be more applied or more public. These fields of practice have been thoroughly reviewed elsewhere (e.g. Field and Fox 2007, Pink 2005, 2007, Abram and Pink 2015). In these literatures applied anthropology has tended in the past to be seen as focussing on undertaking research driven by the needs of clients, while public anthropology has tended to involve a more political stance focused towards societal benefits, and they are infrequently combined in the same project. There are increasingly effective engagements with media for public anthropology dissemination (Abram and Pink 2015). 
However, public anthropology is often seen as not (yet) having met its potential and as Paul Stoller (2016) has emphasised contemporary circumstances call to us to engage 'The Power of Public Scholarship' (add link here to http://www.huffingtonpost.com/paul-stoller/the-power-ofpublic-schol b 10409082.html) arguing that 'the time has come for scholars, guardians of truth and wisdom, to step up to the plate and play a much more central role in the public and political sphere. It is time to use wisdom to drain the fetid swamp of its intolerant hate of everythingother'. Yet there are complications, at least for those mired in the critical reflections that anthropologists often bring to such practice. These have led anthropologists to struggle with the conundrum whereby we are meant to be experts while we cannot claim to be so above our research participants (Sillitoe 2007). The difficulties that some ethnographers have in making their work public has been demonstrated and interrogated (Erikson 2006). There have also been calls for rethinking the collaborative or 'para-ethnographic' ways ethnographers work with 'informants', when their interlocutors are likewise producers of knowledge and are invested in making futures (Holmes and Marcus 2008). These strands of ethnographic reflexivity, critique and heralding of new opportunities and challenges collectively call on us to attend to public, applied or collaborative scholarship as modes of participating in the world. They also signal the complexity and multiplicity of the relationships in which contemporary applied and public ethnographic practices are entangled.

\section{Digital Materialities}

We are concerned with how interrelatedness, knowledge and knowing emerge through applied and public digital and video ethnography practice within a context of digital materiality. By digital materiality we refer to a contemporary context where we the digital and material are no longer seen as relational in the sense that they would be separate then united, but are instead encountered as integral to something that they cannot constitute without each other. Theoretically this means that digital materiality is processual since 'digital materiality does not define "something" done, but a process of becoming. Digital materiality refers to the making and to what emerges of these entanglements, not to a state or a quality of matter' (Pink, Ardevol and Lanzeni 2016: 10-11). This understanding of the environment and the things and processes that constitute it plays a dual role in defining the theoretical and methodological understanding of our practice and its context: it provides a theory of the everyday worlds, technologies and activities in and about which we undertake ethnographic research; and it informs how we design and interpret processes of research, analysis, intervention and dissemination, since our ethnographic and creative practices are undertaken in this digital material world and participate in making new digital materialities.

In a practical sense we discuss how using digital technologies within, documentary video practice, video ethnography, and design documentation offer ways to engage (with) stakeholders in applied (Pink 2007) and public projects that exceed conventional anthropological ethnography (Pink and Abram 2015). These possibilities go beyond those of existing written text-based literatures in applied and public ethnography and in the conventional uses of ethnographic film. 
They require us to attend to the new forms of mediated knowing that emerge as applied and public ethnography become blended with digital and visual practice.

\section{Stakeholder ethnography}

We propose stakeholder ethnography in a practical sense, because it encompasses different categories of partners in research. It invites us to consider who might have a 'stake' or interest in research and its outputs. It evokes for us the idea of someone or organisation coming 'in' to a project, and placing something of value in the mix, rather than the idea of doing commissioned work for a person or organisation. Moreover the term stakeholder, reaches out beyond academia through a terminology that is accessible to partners in research who are not versed in the existing anthropological concepts that are commonly used to refer to such complex sets of relationships, or with the debates underpinning them. This includes researchers themselves and the disciplinary fields they might contribute to, the users or those who commission applied work, wider publics, different groups of expert participants, as well as those who might turn to it in the future. The notion of the stakeholders is an alternative to that of power-holders. It contests the idea that relations of power have to be at the centre of the analysis of ethnographic relationships, and seeks an alternative to the idea of research as a set of power relations. This approach takes the view that collaborations with research partners are developed because all parties involved want to undertake the research. Here power is not exercised in the context of who defines the project: it is a shared agenda, not an applied anthropology agencyclient relationship. Participants become involved because they are interested, even if they can commit little time, and they approve uses of their materials. The examples we discuss are of applied and potentially interventional or future-making ethnographic practice undertaken in environments and research projects that focus on themes of environmental sustainability and futures. Such 'big' questions are frequently implicated in contemporary government, organizational and university research agendas, either as explicit research and change making ambitions, or indirectly as underpinning but vital considerations for organisations, and therefore provide good examples. However this article is not specifically about sustainability research, but rather sees it as one possible example of stakeholder ethnography. Applied research that supports the development of objects, products, services and the design of change processes often needs to attend to how these would be implicated in and support environmental sustainability agendas and processes (as they are variously conceptualized). Applied, experimental, interventional, public and activist ethnography, can have a future orientation - which itself calls for reflexive interrogation of how we conceptualise and seek to intervene in possible, imagined or potential futures and the 'technologies of the imagination' (Sneath et al 2009) that contribute to them. However, as discussed here, working on such themes as futures and sustainability as applied and academic ethnographers, also involves partnering with other stakeholders in these areas. These can range between academics from one's own or other disciplines, creative practitioners (see Carlin et al 2015 link to http://www.axonjournal.com.au/issue-8-1/essaying-fabpod), designers (see Pink, Akama and contributors 2015 link to http://d-e-futures.com/projects/uncertainty/, or industry research partners who are concerned with contributing to future sustainability, and with 
NGOs or social movements likewise seeking to secure a sustainable future (see Pink 2015 link to http://www.hca.westernsydney.edu.au/gmjau/?p=1936), and with the agendas of national research funding councils. There is moreover, beyond conventional applied ethnography, the possibility that we have a responsibility to disseminate research to wider publics and hope that it will engage their imaginations.

The projects discussed here involved an interdisciplinary and future-focused approach to applied ethnography. They draw on existing bodies of applied and public anthropology practice (Fox and Field 2007, Sunderland and Denny 2009, 2012, Beck and Maida 2015, Pink 2005, 2007, Pink and Abram 2015, Pink, Fors and O'Dell 2017) and on design anthropology, which involves applying anthropology, albeit labeled differently and with its own growing theoretical corpus (Gunn and Donovan 2012, Gunn, Otto and Smith 2013). Here our interest is not in presenting or reporting on their research findings per se, but the visual and digital elements of their applied and public crafting and/for dissemination, in how ethnography emerges as an entangled practice, the implications of doing stakeholder ethnography in a context of digital materiality, and how these shifts might refigure relationships between participants, research partners and publics. First we introduce the projects, to show the key relationships with industry and other institutions, , interdisciplinary researcher colleagues, research participants, publics, and pedagogical partners, seeing all of these as different types of stakeholders. It is through these uses of digital technologies, and our intention to address multiple stakeholder groups, that this approach differs from existing academic, applied, public and design ethnography; since it seeks to bring these different fields together within the same research and dissemination projects.

\section{Ethnography in the Energy Research Field (Sarah Pink and Kerstin Leder Mackley)}

To enter into the interdisciplinary field of energy demand research entailed stepping into a field of hopes, aspirations and fears - where fears about climate change, hopes for research success and aspirations to have 'impact' were part of the environment. We need to be conscious of the constructed, political and contested nature of sustainability discourses and how agendas that seek to mitigate climate change through particular disciplinary and interdisciplinary research strategies and calls are implicated with governmental agendas (Shove 2010). The work discussed here could not be separated from this context. Energy demand reduction research is related to a wider global and politically endorsed (in some places) agenda to mitigate climate change, and the LEEDR project was developed in the context of the UK government's carbon emission reduction goals. 

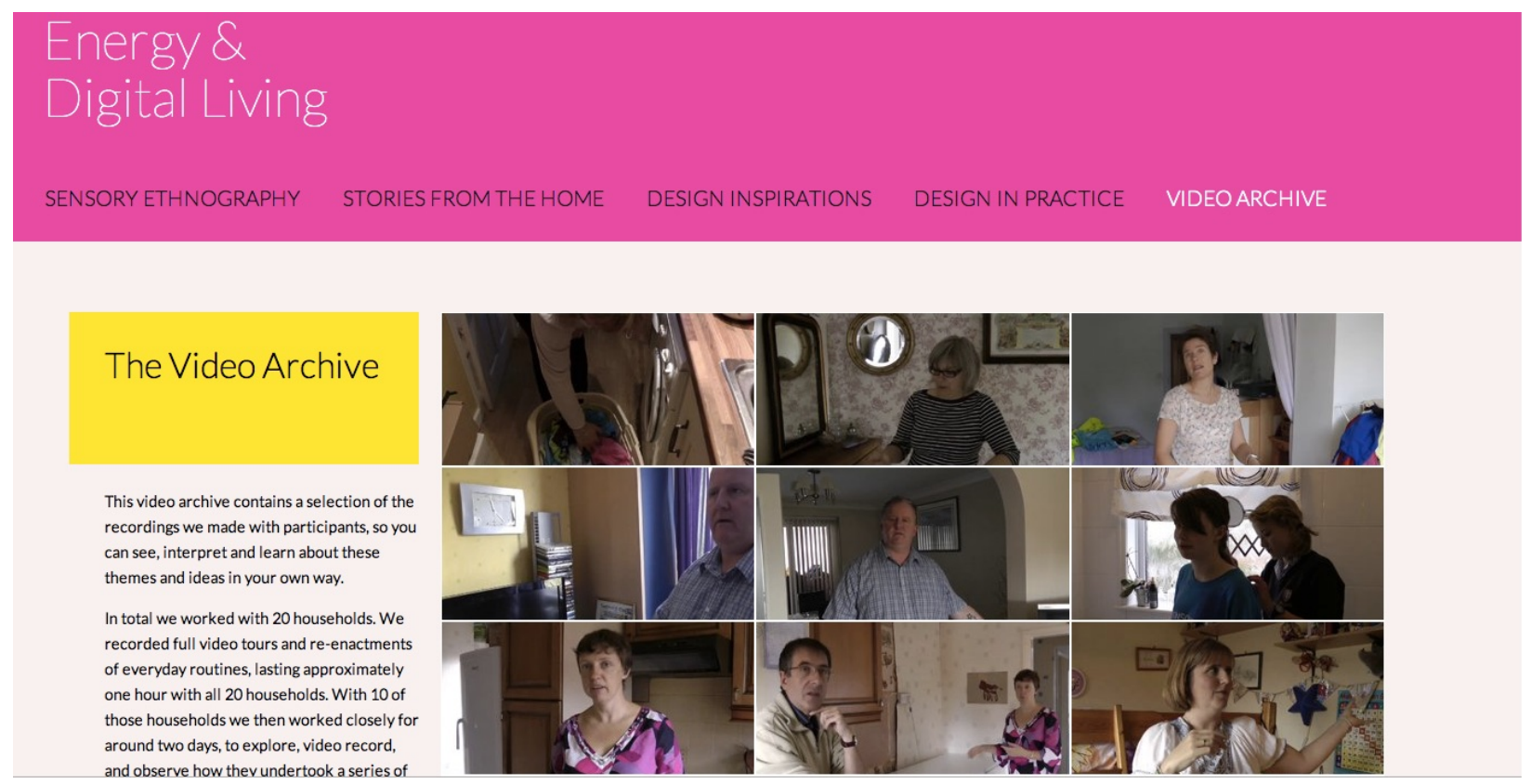

Figure 1: The video archive page of the Energy and Digital Living web site. Copyright LEEDR, Loughborough University.

The Energy and Digital Living web site (2014) is one of several publicly disseminated outputs of the larger Low Effort Energy Demand Reduction (LEEDR) project - a four-year interdisciplinary project based at Loughborough University, UK, funded by the Engineering and Physical Sciences Research Council (project information is here on the LEEDR web site http://leedrproject.co.uk/), and carried out in England. The LEEDR project aimed to make a series of digital design interventions, which would enable people to easily reduce their energy demand in their homes. As the CI responsible for the ethnographic strand of the project Sarah Pink, with Kerstin Leder Mackley and Roxana Morosanu, developed video ethnography research in collaboration with colleagues from design and engineering disciplines who undertook design research and practice, and engineering measurement and monitoring research into energy use. The Energy and Digital Living web site brings the ethnographic and design research into a public domain in order to engage with a range of potential audiences and stakeholders as discussed below.

Both projects discussed in this article were initiated in relation to wider agendas and involved teams with the relevant expertise to address challenges that were already defined. In the LEEDR project these configurations were complex. The project was funded within a United Kingdom Research Councils (RCUK) call for interdisciplinary projects. Our ethnographic strand connected alongside engineering (representing several engineering disciplines) and design strands. Working within as part of LEEDR meant that our ethnographic team was therefore partnered with our colleagues from other disciplines and also with the wider research council agenda. The project was also industry partnered through our engineering and design colleagues. LEEDR situated our work within the context of a wider set of projects through the Transforming Energy Demand Through Digital Innovation TEDDI network 
(https://teddinet.org/projects/buildteddi/leedr-low-effort-energy-demand-reduction/). In this sense the project was set in a context of digital materiality in a number of ways, since we were concerned on the one hand with how participants engagements with digital technologies were implicated in present and future energy consumption, as well as the ways that digital technologies were integral to our research and dissemination processes. This was moreover represented in how the digital video ethnography methods we developed generated interest amongst other qualitative researchers in TEDDI which inspired us to disseminate our methodology through Energy and Digital Living). In the LEEDR project the focus on the ethnographer-participant encounter in traditional accounts of ethnographic practice was decentred. Participants volunteered in response to advertisements or word-of-mouth introductions to the project. Over 60 households volunteered to participate from which a sample of 20 was selected. The participants were not solely recruited to the ethnographic strand of the project, as they also needed to fulfill criteria set by the engineering and design researchers (details of the recruitment materials are here https://dspace.lboro.ac.uk/dspace-jspui/handle/2134/16860). The ethnography team was neither the first nor the only point of contact for the participants, meaning that we needed to be aware not only of how we were impacting on their lives through our own research process, but to consider how this was situated in relation other activities they were participating in. Moreover, participants tended to have an investment in the idea of reducing their energy consumption, and thus their aspirations were coherent with the wider aims of the project, rather than simply being complicit with, or developed relationally to the traditional anthropologist's aim to generate empirical and theoretical understandings. Indeed we imagined that participants would find the prototype apps and energy use statistics that the designers and engineers created to be more comprehensible than the activities we asked them to be involved in, like reenacting their bedtime routines (Pink, Leder Mackley, et al 2017). We offered participants copies of the videos and other materials produced by the ethnography team as they were produced throughout the whole project. However we expected they would find the final outputs of the project developed by designers and engineers, relating to digital design interventions and energy measurements more interesting than our videos (a template of the final feedback book created for participants is available here https://dspace.lboro.ac.uk/dspacejspui/handle/2134/18528).

Working across disciplines and in teams offers new opportunities to work with people who may bring different perspectives to projects. We have written about these experiences and the role of video in our working practices and team communications with designers and engineers elsewhere (Leder Mackley and Pink 2017). These experiences offered interesting ways to consider our colleagues as stakeholders in our ethnographic work, and to seek ways to make our findings about how people lived with energy in their homes accessible to them through video. This situatedness of the participants and research team members was however not as straightforward as it might seem: while the LEEDR participants were often keen to save energy, and in this sense were complicit with the aims of the project, our ethnographic research revealed how they were often hindered in this. As demonstrated in this video where Lee demonstrates his 
bed time routine, (https://vimeo.com/103768077) being conscientious about switching things off cannot always be consistently applied in the same home. Or, as the example of another household demonstrates, it is not always possible to use lower-cost electricity at night due to the contingencies of people's everyday material, social and sensory lives (Pink and Leder Mackley 2012 http://www.socresonline.org.uk/17/1/3.html). Thus we might see participants as stakeholders in the wider project's objectives to find low-effort ways to help people reduce their energy demand, and their relationship to the ethnographic encounters being situated in relation to this. Yet the ethnographic research process simultaneously interrogated these relationships to reveal the complexities and contingencies through which their ambitions and practical ways of living play out. These were also some of the key insights that we wished to disseminate to our interdisciplinary research team.

When we started LEEDR in 2010, anthropological and ethnographic studies of energy use were still few and far between, the earlier work of Rick Wilk and Laura Nader in the US, had not been followed by many others in the ensuing years. There has since developed a stronger anthropology of energy (eg Nader 2010, Strauss et al 2013). However there was at the time an increasingly established body of sociological and psychological and human geography studies in this field, often based in interview studies. This made writing about energy in academic publications necessarily part of a field of interdisciplinary debates, where we came to see the proponents of disciplinary agendas as additional stakeholders in this field. Therefore, to enter this new applied research field was to enter an already occupied entanglement of debates, activities and discourses, some of which were relatively mature, and some of which concerned disciplinary claims within the social sciences. This raised the question of if there was a need to plunge an anthropological stake into the field of energy research and if our project was a vehicle through which to achieve this, this was not our priority. We focused our contribution interventions that sought to shift thinking in in interdisciplinary fields, including design research, i rather than towards the discipline of anthropology itself (although Roxana Morosanu (eg Morosanu 2016) has produced excellent contributions to anthropology through her work on the LEEDR project).

\section{Ethnography, Industry and Documentary (Sarah Pink, Nadia Astari and John Postill)}




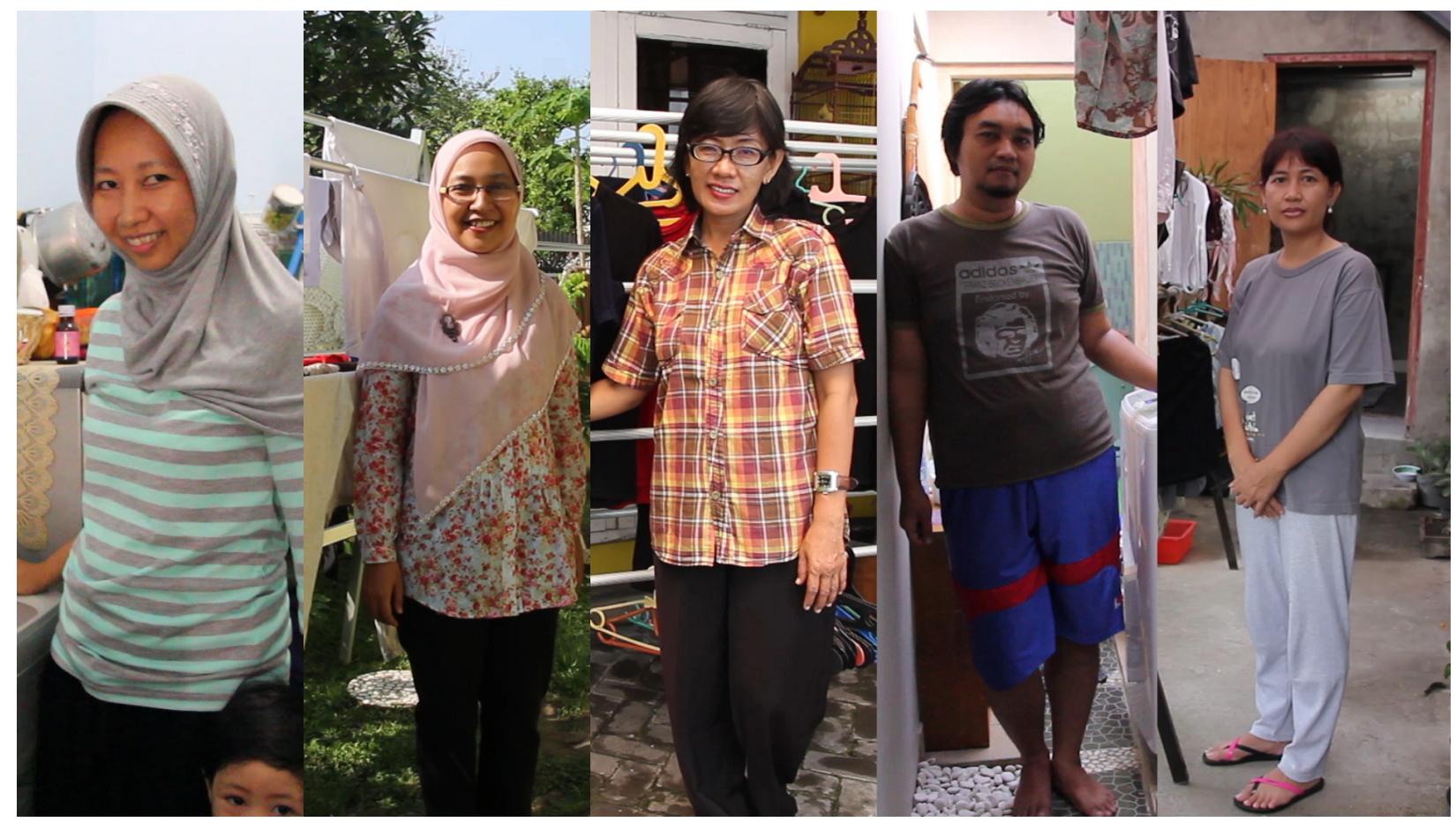

Figure 2: Participants in the Laundry Lives film. Copyright Sarah Pink and Nadia Astari 2015.

Laundry Lives (2015) is a documentary video co-Directed by Sarah Pink and the documentary maker Nadia Astari. It was an output of the Complex, Clever, Cool project led by Pink, involving John Postill, Nadia Astari in the fieldwork, and wider group of colleagues at RMIT University at earlier stages (the sociologist Yolande Strengers and Anna Strempel), undertaken in partnership with Unilever (UK). The ethnographic was undertaken in Australia and Indonesia, by Pink, Astari and John Postill. The project focused on sustainability, laundry, washing machines and digital media and engaged with Unilever's Sustainable Living plan (http://www.unilever.com/sustainable-living/), as well as specific research questions that we had a responsibility to Unilever to respond to through our research findings. One of the benefits to us in collaborating with Unilever was that the project was shaped by existing applied research questions, and thus was informed by the organisation's existing broader knowledge, as well as by the expertise of our direct collaborators in the organisation.

The Laundry Lives film does not disseminate all of our research findings but makes an argument for attention to the particularities of how people already do laundry and their hopes for the future design of sustainable products and services. It therefore seeks to contribute to a public pedagogy and a design brief around issues relating to water and environmental sustainability, and presents an understanding of cultural specificity, everyday life improvisation, and how the contingencies of the material, infrastructural, professional and social elements of everyday life sometimes make sustainable living difficult to achieve.

The Indonesian fieldwork and filmmaking process set the project apart from conventional anthropology or visual anthropology in a number of ways. We took a team ethnography 
approach to combine expertise beyond that which resides in a single researcher and filmmaker. John Postill is an experienced anthropologist of South East Asia, who is fluent in Indonesian. Nadia Astari is an Indonesian documentary filmmaker. Sarah Pink had since 1999, undertaken a series of video ethnographies about everyday life in the home, including ethnographies of laundry (the LEEDR project which included laundry within its brief is one example), and is experienced in designing and undertaking design-focused ethnographic projects with industry partners. This collaboration continued into the documentary post-production process, as Nadia created a structure through which she and Sarah could workshop the documentary script, towards editing and finalising the film.

Similar to the LEEDR project, some participants in Indonesia were invested in environmental sustainability agendas. In this particular cultural and national context participants had specific concerns relating to being able to access enough water for their laundry, using products that would ensure that the items were clean, and fears about damaging delicate items. As was also a finding in the LEEDR project, however, one themes of the film reflects the very point that it is not always easy to live out these commitments in relation to the demands and contingencies of everyday life. As the following film extract demonstrates, participants explained both their aspirations towards sustainability, and the real life contingencies that mean that it is difficult for them to be able to use environmentally friendly detergents or reduce their water consumption. Here, for instance Lia speaks about some of the challenges this involves https://www.youtube.com/watch?v=lRyGlTN3edU. Indeed in the research that underpinned and informed the Laundry Lives documentary we invited participants to share with us their hopes and concerns for their domestic and family futures. https://www.youtube.com/watch?v=wcQsPJsarGQ

The Laundry Lives participants have a voice about an environmentally sustainable future, and take the steps they can, within the limitations of the contingencies of their everyday lives and wider aspirations. In this sense they share our aspirations for a change-making agenda, and can be seen as stakeholders in our work in two ways. First in our research project which in part sought to understand better how sustainability interventions might be created through laundry. Second in the objectives of our film, which seeks to participate in making a public pedagogy about the very need to engage with such participants as partners in future-making through design.

Once we had completed the documentary our collaborative process continued. As part our agreement with Unilever, and as is usual in our industry partnerships, the work needed to be approved by the organisation before it was disseminated publically. As an outcome of this process, whereby the documentary was thoroughly reviewed, we were delighted to be able to include the names of our direct research partners at Unilever, as well as the organisation itself in the film credits, and to also treat this as an acknowledgment of our understanding. Before the film was screened in public Nadia Astari showed it to the participants, back in Yogyakarta in Indonesia, with most at a group screening she arranged at her home. This meant they could view and approve the film before it was released, ensuring they were happy with the way they were 
represented. The finished film has subsequently been screened both within Unilever, at academic conferences and a film festival

However subsequent to its making the question of how the documentary might best be used as a form of public scholarship remained pending. It did not feel like a film festival film, and focused on a mundane theme, albeit one that we believed was important. To interrogate this question further Pink returned to the project the documentary had emerged from and the issues it raised, to suggest that rather than standing as a classic ethnographic documentary, Laundry Lives felt more like a design ethnography documentary. To explore this she arranged a screening of the film within an ethnography and documentary series held by the Digital Ethnography Research Centre (http://digital-ethnography.com/) at RMIT University, which brought together an audience of filmmakers, designers and ethnographers. She asked participants to consider if the film would work as a design brief, and as an outcome of this the film will be screen as a brief to students in a design studio in 2017, and is framed as such through the narrative developed around it and its use as a design ethnography documentary on the Laundry Lives website (http://www.laundrylives.com/design-ethnography/). Laundry Lives as a film and a web site are not simply made to view, but they are intended to generate design practice and ways of thinking about sustainability, products and services, and thus participate in a digital-material environment.

\section{Re-thinking ethnography as an entangled practice}

As an entangled practice, applied ethnography is inseparable from the stakeholders and audiences through which it is made meaningful. As the two projects outlined above demonstrate this can involve complex, and sometimes unexpected layers of relationships. For example; when Pink began to develop the LEEDR sensory ethnography methodology she did not imagine that it would be disseminated to other teams or through a web site; and when she first conceptualised the video ethnography that the Laundry Lives documentary emerged from, she did not imagine that it would necessarily become a documentary, or that it this could be thought of as a design brief.

Perhaps most importantly, both projects show how while the ethnographer-participant relationship remains key, it is diffused in various ways. Admittedly some presences beyond just the people who anthropologists conventionally called 'informants' were always part of academic research processes and were acknowledged as shaping the research context; for instance the roles of gatekeepers, national contexts and what was permissible. Moreover in applied research contexts the inputs and needs of clients or collaborators have always been acknowledged as playing a role (e.g. see Pink 2005, 2007, Buckler 2007, Cefkin 2009, Sunderland and Denny 2009, Field and Fox 2007). Yet often conventionally in anthropology the aspirations, needs, and at worst problematic demands of such clients are framed to be at odds with the values of conventional anthropological ethnography. For instance Sunderland and Denny write about the difficulties they have had in communicating ethnographic understandings to clients using video (2009), the roles of anthropologists in overseas development projects have been refigured in ways that are challenging to ethnographic sensibilities (Green 2005) and client expectations that anthropologists should be an experts go against the grain of an anthropological sensibility to the 
idea that it is actually local people (rather than anthropologists) who are experts on their own worlds (Sillitoe 2007).

Doubtlessly these challenges in bringing together different expectations and interpretations of ethnographic findings and materials exist. However we argue that a different type of resolution is needed, in order to reduce what often appears (perhaps unintendedly) a tendency to put anthropology up against other disciplines and practices, as a more critical discipline. Significantly this involves refiguring the conceptualization of ethnographic knowing as conventionally being emergent from the relationship between researcher and participant, and as a discipline that (in part due to its reflexivity and need to purge the moral burden of its past tendency to objectify and of its colonial heritage) respects indigenous and local knowledge but often appears to have little respect for much else. This is not to say that anthropologists are not often right in their critiques of contemporary societal discourses, structures and beliefs. However our point is different, because it emphasises the possibility of retaining a critical consciousness and conscience, while collaborating to learn and work with multiple stakeholders who inhabitour projects and our wider futures. Elsewhere Pink has conceptualized this as an extension of the 'ethnographic place' - that is the changing configuration of things and processes that cluster around ethnographic work (Pink 2015). In a contemporary context, of applied ethnographic practice specific constituents populate the 'ethnographic place'. These include, those who inhabit with us the site of the research encounter itself, co-researchers in multi-skill or multi-expertise teams, and the indirect presence of interdisciplinary partners from universities and other organisations.

\section{Applied and Public Impact in a Context of Digital Materiality}

There are two key reasons for engaging digital video ethnography methods in applied research. First because, as for any ethnographic encounter, video methods provide ways to work collaboratively with research participants to learn and know about their everyday life experiences. These techniques take advantage of the possibilities offered by digital video for the participant to use their whole body to show they ways that they experience everyday life activities, in the environments and with the sensory, material and digital elements of those worlds present (Pink and Leder Mackley 2012, 2014). This offers possibilities for empathetic forms of viewing and working with the materials both for researchers and for other viewers, keeping in mind the idea that video does not simply show what is captured through the lens, but rather the way that the video maker was her or himself situated in the world (MacDougall 1998, 2005). Simultaneously video provides researchers ways of showing participants what we are doing in research, by sharing video materials and outputs with them. This creates a form of transparency and potentially trust and involvement from participants. In the context of research such as that discussed here, which has involved multiple stakeholders the processes of reviewing video can be time-consuming, because researchers may ask participants to approve lengthy recordings. However this is valuable because it means that through consultation the participants' stake in the research project becomes acknowledged beyond their simply being 'informants'. Rather it gives them opportunities to change their minds on the basis of being more fully 
informed than they were when they originally signed a consent form. This approach therefore recognizes participants as experts and as having a role in the research process.

Second however, beyond the bounds of traditional writings on the ethnographic encounter (e.g. Clifford and Marcus 1986), video is important for engaging other stakeholders with the ethnographic encounter, and the ways of knowing with participants that have emerged from this. This approach is fundamental to applied visual anthropology, where documentary filmmaking and associated forms of advocacy have been engaged (e.g. Durington 2007, Camas et al 2007). However these have not been without their problems (see Sunderland and Denny 2009) and recently further exploration has been undertaken looking at how video can also be used to engage across interdisciplinary research teams (Leder Mackley and Pink 2017) and with industry stakeholders (Pink, Fors and O’Dell et al 2017). In this sense the idea of using ethnographic video, or video ethnography to engage stakeholders with research arguments, outputs and advocacy is not new, however, in a context where the impact agenda increasingly co-implicates academic and applied research, the role of video is all the more pertinent. This is particularly so in a context where the environments in which we live and research, and the tools of our research are characterised by a form of digital materiality - of which digital video is just one element.

Digital materiality is, we argue, fundamental to understanding the possibilities of contemporary stakeholder ethnography. It refers to the idea that we inhabit a world where the digital and material are increasingly entangled, and where such statements themselves will very soon appear anachronistic. Bringing these arguments into play with the question of how we develop digital and visual applied ethnography in multi-stakeholder research projects offers an additional layer of thinking to ethnographic practice. This is because it implies that our forms of engagement with stakeholders need not be face-to-face or paper-based but are in fact more likely to happen in ways that are mediated through emergent forms of digital materiality.

\section{Reconceptualising the Participant in Stakeholder Ethnography}

The ways that we know and what we can know as ethnographers, have been interrogated thoroughly over the last 40 or so years. The most conventional form of ethnographic knowing, which has been established most deeply since what has been called the 'writing culture debate', initiated largely in the work of Clifford and Marcus (1986) was based in the idea that we learn and know as ethnographers in relation to research participants. This work, and the extensive literature that followed (e.g. e.g. Clifford and Marcus 1986, Kulick and Willson 1996, James et al 1997, Harris 2007, Pink 2013, 2015), firmly established the place of who is still sometimes called the informant in ethnographic research as an interlocutor, whose voice should be acknowledged and whose intersubjective relationship with the ethnographer needed to be reflexively interrogated. There has also been an interrogation of what is best referred to as ethnographic knowing. Here, departing from the idea knowledge can become a static object, the concept of knowing has offered a more dynamic model of how ethnographers ongoingly learn through their encounters (eg Harris 2007). While this does not preclude the possibility that we might write up what we know at any one moment, it allows for an acknowledgment that what we 
know about the world is always in the making, is always relational and is always being made and remade with others. This encompasses the idea that anthropological ethnography involves researching with rather than about people (Ingold 2008).

The idea that we make ways of knowing together with ethnographic research participants has tended to dominate revised ways of understanding the production of knowledge through ethnographic research. A further alternative vision of the relationship between ethnographer and clients is proposed by Holmes and Marcus, with regard to research experiments in which the clients are both skilled professionals themselves and the subjects of research. What they call 'para-ethnography' is specific to situations confronted with the question of: 'How do we pursue our inquiry when our subjects are themselves engaged in intellectual labors that resemble approximately or are entirely indistinguishable from our own methodological practices?' (Holmes and Marcus 2008: 596). They propose a methodology that 'demands that we treat our subjects as epistemic partners who are not merely informing our research but who participate in shaping its theoretical agendas and its methodological exigencies' (2008: 596). This, they suggest will lead to scenarios where 'our analytical interests and theirs can be pursued simultaneously, and we can share insights and thus develop a common analytical exchange' (2008: 596). For Holmes and Marcus much of what is conventional to anthropological ethnography remains in these epistemic partnerships, in that, for instance the figure of the informant remains, although in a new guise. As they put it 'Making ethnography from these found para-ethnographic narratives redefines the status of the subject or informant and asks what different accounts one wants from such key figures [ie what they call the 'para-ethnographer'] in the fieldwork process' (2008: 597). Holmes and Marcus's para-ethnography resonates with some of our concerns, in that the 'new ethnographic subject — an accomplished autodidact', who they write of (2008: 578), forms part of the entanglements we are concerned with. Moreover for them, para-ethnography concerns 'analytical engagements with formations of culture that are not fully contingent on convention, tradition, and the past, but rather, constitute future-oriented cognitive practices that can generate novel configurations of meaning and action' (2008: 578).

The stakeholders in research discussed in this article also have particular future-oriented visions of the world. However, in the context of an applied research and design ethnography agenda this future orientation is less novel, than it is to the conventional anthropological ethnography that Holmes and Marcus comment on; a point which in itself suggests the pertinence of bringing applied scholarship and practice to bear on debates that sit at the centre of conventional anthropology. Applied and public ethnography thus exceed these debates as they have emerged in mainstream anthropology, since when multiple stakeholders are involved, such visions need to be situated within the complexities of real world applications, which means going beyond the idea that the ethnographer-informant dyad is necessarily the centre, or the only centre of the ethnographic encounter. Decentring the ethnographer-informant relationship is however challenging in some ways. This is because the idea of participants in research as interlocutors and as people we come to know the world with has provided both an ethical and methodological stance for academic anthropology. If this relationship is decentred, then we need to consider 
how, then, the integrity of the ethnographic encounter is maintained in the face of other stakeholder relationships. An interrogation of the projects discussed above offers some suggestions:

Most participants across the projects aspired to live in environmentally sustainable ways, even if they did not necessarily achieve this perfectly. While none were 'clients' or sponsors who had funded or commissioned the research we undertook, they simultaneously volunteered to participate in ways that entailed a choice different to that made by the 'informants' of conventional anthropological studies. In doing so they contributed in ways that influenced the outcomes of the projects. They often also acknowledge that our projects pursued agendas that coincided to some extent with their ambitions, or that would give voice to these ambitions or the difficulties they faced in realizing them. The principles and practice behind the sensory and visual ethnography research methods used in the two projects are discussed in detail elsewhere (e.g. Pink 2013, 2015, Pink and Leder Mackley 2012, 2014). They include video tours and reenactments, documentary making, more conventional ethnographic hanging out, and interviewing. They are reflexive methods, designed specifically to investigate the tacit, normally unspoken, sensory and emotional elements of the everyday, as well as explicitly verbalized discourses. Because it tends to make the relationships of video making explicit visual anthropology practice has often pre-empted concerns raised in written anthropology. This refers particularly to the reflexive positioning of researcher/filmmaker and participants. Each project sought to position participants through the notion of a 'shared anthropology', which for Jean Rouch meant that the subjects of his films were always the first audience (Rouch 1974). The LEEDR participants viewed and approved all footage before it was screened or posted online. In nearly all cases they approved the clips that we proposed, although in some cases participants preferred not to be represented in online videos or made particular specifications about what could be represented. The Laundry Lives participants met with Nadia in Indonesia to view our film together, or viewed it in their own homes and approved it before we screened it in public without asking for any changes. Yet, as Flores notes (2007) it is not always possible to engage participants in sharing the working processes of making ethnographic outputs. Indeed such coproduction demands time and commitment from participants that they might not be able to offer. Seeing participants as stakeholders helps us to re-think this problem. It reminds us to be mindful to the nature of the stake that people might have in any project, that this will vary, that we need to be open to a range of relationships and levels of participation, and that video can become a key vehicle for enabling participants to make choices about this.

Finally in our work the ethnographer-participant relationship was de-centred through our team ethnography approach. Ethnographic fieldwork in each project was undertaken by three people. In the Complex, Clever, Cool project Pink and Postill undertook fieldwork with Indonesians in Melbourne where Pink developed the video ethnography methodology (Pink and Postill 2016) and Postill and Astari undertook fieldwork in Yogyakarta. In LEEDR, Pink, Leder Mackley and Morosanu all undertook fieldwork in England. By using video materials we were able to share our experiences of working with the participants across the team. Some participants 
were only met by some of us on video. However, because we had shared the same video ethnography methodology we could use our own experiences to imagine colleagues' experiences, and therefore became stakeholders in each other's video work as we needed to collaborate to produce and interpret the project materials.

\section{Ethnographic pedagogies}

There are various ways to create pedagogical uses of ethnographic video, and there is a long history of using ethnographic documentary in the teaching of general and visual anthropology. However the new challenge is to create an applied pedagogy, a response to stakeholders outside academia, and to consider society at large as a stakeholder in our work. The projects discussed above begin to show how digital visual ethnography can emerge as a pedagogy that spills into practice-based disciplines and ideally into practice outside academia, in a context of digital materiality. Admittedly however, the idea that public ethnography will educate a wide societal audience would be either naive or arrogant (given that many will be oblivious, uninterested or contesting one). This demands us to ask how, or through what types of interdisciplinary or partnership alliances might digital visual ethnographic practice become active in the world, and what are the pedagogical implications and limits of such practice. There are different answers to this question and we encourage readers to interrogate other forms of engagement and practice. Here we examine this issue specifically in relation to how ethnographic video/documentary materials can be prepared to educate those in disciplines beyond the social sciences, and ideally also to inspire practitioners whose work extends outside academia. We reflect on the potential of Energy and Digital Living and Laundry Lives to educate others, or at least to enable others to think differently as a result of (sometimes guided) viewing. Both projects, have been used in presentations to industry partners and to students and peers, to make points that represent characteristic ways of knowing through ethnography in academic contexts, but that also serve as revealing moments in non-academic dissemination contexts because they show how participants' mundane knowing and expertise is both important but also usually invisible. The following two examples demonstrate how the clips can be mobilised for this purpose:

1) Things are not always what they seem: This is demonstrated in the Energy and Digital Living clips 23 and 32, where participants Alan and Lee shows us how they use light on their ways through the night time home. These clips have been used to demonstrate themes about everyday expertise, one of which is that lighting is not necessarily used for visual contemplation but rather that it is part of more complex embodied sensory ways of knowing our environments. In Laundry Lives this realisation is epitomised in clip 3 where Nadia Astari asks the participants, Ning and Mbok Jinah why they do not actually wash the clothes in the washing machine. They explain that they only use it to spin the clothes because they believe that machine washing will damage them, and therefore prefer to handwash.

Energy and Digital Living clip 23: Alan demonstrates his bedtime routine. https://vimeo.com/101879571 
Energy and Digital Living clip 32: Lee demonstrates his bedtime routine.

https://vimeo.com/103768077

Laundry Lives clip 3: Ning and Mbok Jinah discuss their use of the spin cycle on the washing machine. https://www.youtube.com/watch?v=Aho9_x_RD4U

\section{2) People have their own forms of expertise, and technological innovation is not always the}

answer: This is demonstrated by two clips which involve the use of sticks to solve everyday practical and environmental sustainability challenges that technological solutions might be contemplated for, but could be unnecessary. In Laundry Lives Adi shows how in order to make the most of natural sunlight, he hangs his laundry to dry high up on a runner beneath a transparent roof designed into their house for this purpose. To hang the laundry he uses a stick with a hook on the end. In Energy and Digital Living, Alan explains how he developed a solution so that his family could easily switch off the television and its associated devices at bed time, all of which were hard to reach in the corner of the room behind their stand. Alan kept a stick behind the TV, which could be used to simply poke behind the equipment and switch it all off at the wall.

Laundry Lives clip 2: Adi demonstrates how his family uses a stick to raise the laundry to hang to dry underneath the transparent roof. https://www.youtube.com/watch?v=qfFC5GqtVcQ.

Energy and Digital Living clip 6: Alan demonstrates how his family uses a stick to switch off the TV and related appliances. https://vimeo.com/101362416.

Both Energy and Digital Living and Laundry Lives have been used in teaching and presentations to design students. The uses for Energy and Digital Living are perhaps more obvious since it documents a design ethnography research process. The website has a didactic structure, and has often been used in teaching, workshops and presentations in order to introduce the sensory ethnography methodology or to speak about the project and its findings. The purpose of the Laundry Lives documentary was less apparent to Sarah Pink and Nadia Astari as the film was made. Pink and Astari workshopped the film's narrative based on selected themes that had emerged from the Complex, Clever, Cool ethnography, with the aim of making a film that held an argument about how and why it was difficult for the new middle classes in Indonesia to undertaken everyday tasks such as the laundry in ways that are environmentally sustainable and to situate this in relation to their everyday lives and future aspirations. Later once the film was finished and Pink began to screen and discuss it with colleagues, that she began to consider its relationship to design, and to conceptualise this relationship as a way that the film might have impact in the world. There are plans to use Laundry Lives as a design brief for a practice-based 
studio at RMIT in 2017. Meanwhile the film's web site establishes the possibility of using the film as a design brief, from which new digital-material designs and services could emerge.

\section{Conclusion}

In this article we have explored how a revised understanding and practice of ethnography, through the concept of the stakeholder offers a means through which to create engaged ways of working with research participants, partners, and publics. This means de-centring ethnography from its conventional stance of doing research with research participants (Ingold 2008) to instead broaden the scope of whom we are communing with, the ways that technologies are implicated in these relationships, how we engage with creative practice, and the extent to which we are willing to compromise our critical practice. In doing so, we can take new steps to doing ethnography in the world, in ways that have impact but that are nonetheless reflexive and aware, and that have at their core a responsible form of pedagogy that enables learning to happen at all stages and in all relationships of the research process: between ethnographer and participant; in ethnography teams; across disciplines; between academic, industry and other partners; within national research council calls; and in relation to both traditional classes or studios, as well as wider publics.

The concepts of digital materiality and of the stakeholder are fundamental to the mobilisation of this approach. Since they offer ways to reconceptualise the environments and activities that form part of our contemporary and future everyday and research worlds, as well as the complexities of the relationships that research can entail.

\section{References}

Beck, S. and C. Maida (2015) Public Anthropology in a Borderless World. Oxford: Berghahn. Buckler, S. (2007) Fire in the Dark: Telling Gypsiness in North East England., Berghahn, Oxford

Carlin, D., Y. Akama, S. Pink, A. Miles, K. Brettle, A. Fergusson, B. Magner, A. Pang, F. Rendle-Short and S. Sumartojo (2015) 'Essaying The FabPod: An Improvised Experimental Collaborative Account of the Uncertain Cultural Life and Futures of the Fabpod, as of August 21, 2014' Axon. http://www.axonjournal.com.au/issue-81/essaying-fabpod

Cefkin, M. (ed) (2009) I In Ethnography and the Corporate Encounter: Reflections on Research in and of Corporations. Oxford: Berghahn

Clifford, J. and G. Marcus (eds) (1986) Writing Culture: The Poetics and Politics of Ethnography. Berkeley: University of California Press.

Durington, M. (2007) 'The Hunters Redux: Participatory and Applied Visual Anthropology with the Botswana San' in Pink, S. (ed) Visual Interventions: Applied Visual Anthropology, Oxford: Berghahn

Eriksen,T. H. (2006) Engaging Anthropology: The Case for a Public Presence. Oxford: Berg Field, L. W. and R. G. Fox (eds) (2007) Anthropology Put To Work, Oxford: Berg 
Flores, Carlos (2007( Sharing Anthropology: Collaborative Video Experiences among Maya Film-makers in Post-war Guatemala. In Visual Interventions. Sarah Pink, ed. Pp209-224. Oxford: Berghahn

Green, M. (2005) 'International Development, Social Analysis and Anthropology? Applying Anthropology in and to Development' in S. Pink (ed) Applications of Anthropology. Oxford: Berghahn.

Gunn W and Donovan J (2012) Design anthropology: an introduction. In: W Gunn and J Donovan (eds) Design and Anthropology, Ashgate

Gunn, W., T. Otto and R. C. Smith (eds) (2013) Design Anthropology: theory and practice, Oxford: Bloomsbury Publishing.

Harris M (2007) Introduction: ways of knowing. In: Harris M (ed.) Ways of Knowing, New Approaches in the Anthropology of Experience and Learning. Oxford: Berghahn.

Holmes, D. and G. Marcus (2008) 'Para-Ethnography' in L. M. Given (ed) The Sage Encyclopedia of Qualitative Research Methods. Thousand Oaks, CA: Sage Publications. Pp 596-598.

Ingold, T. 2008. 'Anthropology is not Ethnography', Proceedings of the British Academy 154(11): 69-92.

James, A., J. Hockey, and A. Dawson. 1997. After Writing Culture: Epistemology and Praxis in Contemporary Anthropology. London: Routledge.

Kulick, D, and M. Willson, eds. (1995) Taboo: Sex, identity and erotic subjectivity in anthropological fieldwork. London: Routledge. MacDougall D (1998) Transcultural Cinema, Princeton: Princeton University Press.

MacDougall D (2005) The Corporeal Image: Film, Ethnography, and the Senses, Princeton: Princeton University Press.

Martinez, A. and V. Camas (2007) 'The Rhytm of Our Dreams: A Proposal for an Applied Visual Anthropology' in Pink, S. (ed) Visual Interventions: Applied Visual Anthropology, Oxford: Berghahn

Morosanu, R. (2016) An Ethnography of Household Energy Demand in the UK: Everyday Temporalities of Digital Media Usage. Palgrave Macmillan.

Nader, L. (ed) 2010 The Energy Reader. Oxford: Wiley-Blackwell.

Pink, S. (2005) (ed) Applications of Anthropology, Oxford: Berghahn.

Pink, S. (2007) (ed) Visual Interventions: Applied Visual Anthropology, Oxford: Berghahn

Pink, S. (2007) (ed) Visual Interventions: Applied Visual Anthropology, Oxford: Berghahn.

Pink, S. (2013) Doing Visual Ethnography, second edition, London Sage.

Pink, S. (2015) 'Ethnography, co-design and emergence: Slow activism for sustainable design' Global Media Journal 9(2). http://www.hca.westernsydney.edu.au/gmjau/?p=1936

Pink, S. (2015) Doing Sensory Ethnography, second edition, London Sage.

Pink, S. and J. Postill (2016) 'Student migration and domestic improvisation: understanding transient migration though the experience of everyday laundry' Transitions 
Pink, S. and K. Leder Mackley (2012) 'Video as a Route to Sensing Invisible Energy' Sociological Research Online, February 2012, on line at http://www.socresonline.org.uk/17/1/3.html

Pink, S. and K. Leder Mackley (2014) 'Reenactment Methodologies for Everyday Life Research: Art Therapy Insights for Video Ethnography' Visual Studies 29(2), pp.146-154.

Pink, S. and S. Abram (eds) (2015) Media, Anthropology and Public Engagement, Oxford: Berghahn

Pink, S. and Y. Akama and contributors (2015) Un/Certainty. iBook, download from http://d-efutures.com/projects/uncertainty/

Pink, S., E. Ardevol and D. Lanzeni (2016) 'Digital Materiality: configuring a field of anthropology/design?' in S. Pink, E. Ardevol and D. Lanzeni (eds) Digital Materialities: anthropology and design. Oxford: Bloomsbury

Pink, S., K. Leder Mackley, R. Morosanu, V. Mitchell and T. Bhamra (2017) Making Homes: ethnography and design. London: Bloomsbury.

Pink, S., V. Fors and T. O'Dell (eds) (2017) Theoretical Scholarship and Applied Practice, Oxford: Berghahn

Rouch, J. (2003 [1973]). The camera and man. In Cineethnography: Jean Rouch, edited by S. Feld. Minneapolis and London: University of Minnesota Press.

Shove, E. 2010. Beyond the ABC: climate change policy and theories of social change. Environment and Planning A, 42, 6, 1273-1285.

Sillitoe, P. (2007) Anthropologists only need apply: challenges of applied anthropology. Journal of the Royal Anthropological Institute, 13(1): 147-165

Strauss, S., S. K. Rupp and T. Love (2013) Cultures of Energy : Power, Practices, Technologies. Walnut Creek, USA: Left Coast Press Inc.

Sunderland, P. and R. Denny (2009) Doing Anthropology in Consumer Research. Walnut Creek: Left Coast Press. 